\title{
FACTORS AFFECTING EFFICIENCY OF RAILWAYS IN TERMS OF SAFETY AT RAILWAY LEVEL CROSSINGS
}

\author{
INARA WATSON ${ }^{1}$, AMER ALI $^{2} \&$ ALI BAYYATI ${ }^{2}$ \\ ${ }^{1}$ School of Engineering \\ ${ }^{2}$ School of the Built Environment and Architecture, London South Bank University, United Kingdom
}

\begin{abstract}
Road traffic accidents are in the top ten of all deaths, with around 1.4 million fatalities and 50 million injuries per year worldwide. Regarding railways, in the EU, there were 1,666 serious accidents registered in 2018 and 442 of them involved level crossings (LCs). The number of accidents on LCs in the EU in 2018 was approximately $27 \%$ of the total number of accidents on railways, but these accidents can be predictable and preventable. The current study investigated the efficiency of railways in terms of accident risk at LCs in 24 countries of the EU. The Data Envelopment Analysis (DEA) method has been applied to evaluate the efficiency of the selected railways in terms of safety at LCs. After extensive study of the subject, the comprehensive list of influencing factors has been identified and seven of them have been selected for further analysis. To investigate the relationship between selected factors and efficiency score of railways in terms of accident risk at LCs, the IBM SPSS software package has been deployed. The results show that GDP per capita and density of population in the selected countries have a strong influence on the efficiency of railways in terms of safety at LCs. The expected outcome of this research may contribute to a better understanding of the factors that influence the efficiency score of railways in term of accident risk at LCs and may help to develop preventative measures.

Keywords: accidents, efficiency score, influencing factors, level crossings, railways
\end{abstract}

\section{INTRODUCTION}

In 2018, there was 1,399,256 deaths in road traffic accidents worldwide [1]. Regarding railways, in 2018 in the EU, there were 853 fatalities from railway accidents and $27 \%$ of them occurred at LCs [2]. The large number of scientific publications are dedicated to evaluating and analysing the safety at LCs and proposing new measures for improving safety. The main measures can be divided into three groups: technical improvements, education of public and enforcement penalties on traffic offenders. Despite the huge efforts of railway operators in the EU in the last years to improve the safety at LCs, the number of accidents and fatalities are still stable.

Benchmarking the efficiency of railways in terms of the safety at LCs will indicate the difference in performance and will help to find the factors that can influence this performance. Comparing the efficiency of safety at LCs is a difficult target as different railways apply different technologies, located in different topographic locations, and serve different sizes of population. In addition, the railways were developed in different countries at different times and standards.

The main motivation of this study is an under-researched area and shortage of knowledge in:

- Evaluating the efficiency of railways in terms of safety at LCs in Europe.

- Identifying the key factors that influence the safety at LCs and how to improve it.

*ORCID: http://orcid.org/0000-0002-4976-3776 
The problem is that the railways around the world are working on improving safety at LCs but not everything depends on the railways. Because of this when we compare performance of different railways around the world or in the EU there is a need to take into consideration factors that do not directly depend on the railway.

The novelty of this study is that the large number of studies that have been taken before looked at many factors that can be related with accidents at an individual LC or types of LCs. To the best of my knowledge, there has not been a study before that looked at factors that can influence the efficiency of railways as a whole system.

This study proposes an integrated approach to evaluate the safety efficiency at LCs of the selected railways and the factors that affect safety at LCs.

- NVivo is used to prepare and analyse the qualitative data.

- DEA is used to compare and evaluate the performance and efficiency of the selected railway systems.

- IBM-SPSS is used to identify the factors that influence the performance of the selected railways and to statistically analyse the results of the DEA and the selected variables.

The possible correlation between changes in the economic status of the railways and their safety performance was studied by Evans [3]. The main countries that were investigated are GB, the EU and the USA, included are some analyses of Finland and Japan, and Evans [3] did not find any evidence in deterioration of safety level of railways due to privatisation or economic deregulation of businesses. The other way around, there was evidence that due to improving the financial performance of the railways the operators had the possibility to renew and improve their assets, which in turn improved the safety level of railways. This is an important finding that shows that the efficiency of railways in terms of the safety is strongly correlated to the financial opportunities to renew and improve the railways assets. Therefore, when comparing the railway operators from different countries in terms of safety at LCs there is a need to consider the level of economic development of these countries.

The comparative analysis between Italy, Greece, Finland, France, Norway, Spain and Turkey in terms of safety at LCs had been carried out by Carrese et al. [4]. The analysis focused on details of collisions, victims, road and railway environment, LC characteristics. Carrese et al. [4] found that many accidents which involved pedestrians, cyclist and cars have been caused by illegal crossings due to the high waiting times and most of them occurred during the daytime when road traffic is higher. The accidents at LCs that involved trucks had mostly happened due to specific deficiency of LC layouts, such as poor visibility or lack of space to complete the turning movement. The vehicle and train speed limits are not influential in LC accidents, but it can be related to the seriousness of accidents. Also, Carrese et al. [4] did not find any correlation between train traffic and the number of accidents at LCs. The accidents were mainly caused by incorrect behaviour of road users at LCs. Carrese et al. [4] did not take into consideration level of economic development in selected countries and density of population which can be critical factors in comparative analysis between different countries.

A new approach to evaluate and compare safety at railway-road LCs in the EU had been proposed by Djordjević et al. [5]. The authors have used the improved non-radial DEA model with two inputs and three outputs. The inputs were a number of LCs and number of assets (total number of locomotives and railcars), and the outputs were railway passenger volume, 
railway freight volume and a number of accidents at LCs. Djordjević et al. [5] have found that UK, Germany and Sweden had the lowest fatality risk at LCs for the period 2010-2012 and Croatia, Slovenia and Slovakia had the highest fatality risk.

\section{METHODOLOGY}

Many studies have been performed to find factors that can influence the safety at LCs, and they used different approaches and methodologies from personal monitoring of traffic at LCs, using video cameras, online survey, using advanced driving simulators and using the conventional evaluation indicators of the economic efficiency. However, all these approaches looked on safety at LCs, but present research looks on the efficiency of the whole railway system. How efficient railway systems are in terms of safety at LCs in the whole country.

The first part of this research is a literature review of scientific publications related to evaluation, analyses, and measures for the improvement of safety at LCs. The purpose of the study is to answer the questions regarding to the different aspects of safety at LCs and find out the main related factors that influence the safety at LCs in the selected countries in Europe. The combination of several methods and different approaches has been applied to identify the major factors that influence the safety at LCs. To prepare the literature review, the qualitative data analysis software NVivo was applied, as research required a substantial level analysis. The NVivo helped to summarise and evaluate large amounts of non-numerical information. To benchmark the performance of the selected railways in terms of safety efficiency at LCs the Constant Return to Scale Malmquist Index DEA has been practiced. The IBM SPSS is used to find the factors that affect the efficiency of these railways in terms of safety at LCs.

For this research, the railways in 24 countries in Europe are studied and five years of data is analysed. The input is the number of accidents at LCs in the selected countries and the outputs, the number of passenger-km and tonnes-km. The selection of the data is influenced by the data availability and difficulties in obtaining the data. All information gathered from various sources, such as libraries, the Internet and meetings with relevant railway and transport professionals.

For this study, the benchmarking methodology for the railway industry will be used. Benchmarking methodology presumes to compare the performance of the selected railways with railways that are recognised as a leader in the industry to find the best practices and factors that influence it. This analysis is very suitable for the railway industry, as the industry is highly regulated and links between inputs and outputs cannot be clear [6]. Benchmarking the selected railways can give recommendations to the best practices in safety. The package NVivo is used to prepare and analyse the qualitative data. Using this software, different types of data are analysed. NVivo helped to examine the potential relationship between topics.

This study proposes an integrated approach to evaluate the safety efficiency at LCs of the selected railways and the factors that affect safety at LCs.

- NVivo is used to prepare and analyse the qualitative data.

- DEA is used to compare and evaluate the performance and efficiency of the selected railway systems.

- IBM-SPSS is used to identify the factors that influence the performance of the selected railways and to statistically analyse the results of the DEA and selected variables.

The expected outcome of this research will contribute to identifying areas of improvement and contributing to the development and advances of safety at LCs. 
The contribution of the present study comes mainly from the following areas:

- Evaluating the efficiency of the selected railways in terms of safety at LCs.

- Evaluating the relationship of efficiency scores with selected variables by applying IBMSPSS Statistics.

- Distinguishes the factors that contribute to the safety scores for the selected railways.

\section{TYPES OF LEVEL CROSSINGS}

The type of LC depends on the factors such as volume of trains and vehicles, area of location, etc. LCs can be passive or active. Most LCs around the world are passive. The passive LC is equipped with only warning signs such as 'STOP' and a 'ST ANDREW's CROSS', and road markings. It is up to the user to decide when it is safe to cross the line. The safety at Finnish LCs studied by Kallberg [7] and came to conclusions that most of the accidents in Finland occur at passive LCs, with low road and rail traffic and $80 \%$ of all accidents were caused by inappropriate behaviour of road users.

Regarding the active LCs, in addition to warning signs and road markings, the LCs are equipped with warning systems that warn road users about approaching trains. The warning systems consist of flashing lights and sounds, and some have a barrier between the train and road users that close when the train approaches. The safest type of crossings is the grade separation LCs that separates the rail and road traffic by building an overpass or underpass. This type of crossing is the most expensive option. The grade separation LCs apart from safety benefits reduce the congestion on roads, improve traffic flow, reduces noise and air pollution.

The comparison of safety levels at passive and active LCs in Finland has been studied by Laapotti [8] and made the conclusion that active LCs are more effective in preventing accidents. The active LCs provide more information about location of coming trains than passive LCs and because of this can more effectively prevent road users to make errors. However, it was found that current technical and design solutions to improve the safety at actively controlled LCs is not always effective, as it can be used in ways unintended by design and incompatible with safety [9]. The conclusion that LCs equipped with active warning systems are less likely to be violated than those equipped with a passive warning system have been made by Rudin-Brown et al. [10] and found that drivers react sooner to active warning devices at LCs compared to passive ones. In terms of road surface, the results show that rumble strips are unlikely to be effective to improve the behaviour of drivers approaching LCs, they can only provide an additional alerting signal [11].

The factors that may impact the LCs accidents have been analysed by Liang and Ghazel [12]. Despite increased spending to improve the safety at LCs in France in 2014 the number of collisions at LCs reached 100 with 25 fatalities. To predict the annual accident frequency, Liang and Ghazel [12] considered three factors, the average daily road and railway traffic, and the annual number of road accidents. They found that the significant impact on the number of accidents at LCs are mostly caused by the road accident frequency and combination of rail and road traffic volume. This is a significant finding that shows that despite all the effort that makes different railway operators to reduce the number of accidents at LCs some factors are not subject to them, such as frequency of road accidents in a country.

The comprehensive research of road user's interaction at active LCs in urban areas have been carried out by Larue et al. [13]. The main violations from road vehicles were to stop on the LCs or enter the LCs when the lights had been flashing, for cyclists were entering the LCs before the gates had completely risen. The pedestrians had the most traffic violations at LCs. 
Larue et al. [13] concluded that despite of the active protection system at LCs the road users demonstrated the risky behaviour by deliberately violating traffic rules at LCs which was motivated by trying to save time. Larue et al. [13] found that when a first road user violates traffic rules at LCs it is highly likely another road user will follow suit.

\section{LEVEL CROSSING ACCIDENTS AND TYPES OF USERS INVOLVED}

In France, the number of LCs decreased from 18,364 in 2010 to 15,258 in 2018, in Germany in the same period the number of LCs decreased from 17,318 to 13,807 [14]. This trend is observed throughout Europe. The number of LCs are decreasing very sharply, but the number of accidents is still high. There are two types of LC accidents, namely, collision of road vehicles with trains, and collision of road vehicles with LC devices. Drivers do not look carefully for trains before crossing. There are hundreds of near-miss accidents every year [8], and they occur more frequently than accidents. The near-miss accidents will not usually be investigated due to the large number of events. However, these events can have a negative impact on traffic flow, cause train delays and can affect safety of trains if drivers used their emergency brakes and eventually can cause the accidents. The new method for detecting near-miss accidents at LCs from video data of trains has been developed by Aminmansour et al. [15].

Most accidents at railway intersections involved pedestrians, and some estimates reached $75 \%$ of the total number of accidents. In addition, the mortality rate for pedestrians is higher than among car occupants, especially at passive LCs [16]. The lowest fatality rate per traveller have the road vehicle occupants on railway-controlled LCs. The railway-controlled LCs are safer than active LCs, but railway-controlled LCs caused the greater delays on users [16]. The replacement of railway-controlled LC by active LC will give monetary savings from reduction of traffic delays which will outweigh the losses from the increased casualties.

The increased number of accidents between 2003 and 2011 in Australia at LCs which involved pedestrians have been studied by Stefanova et al. [17]. The finding of Freeman and Rakotonirainy [18] show that pedestrians are more likely to deliberately violate traffic rules rather than make errors and suggested that there is a need to develop the injured prevention education schemes that will help to reduce the number of pedestrians involved in accidents at LCs. The low probability of pedestrians violating traffic rules at LCs to be apprehended can be prone to repeat the dangerous habit. These findings have been confirmed by Stefanova et al. [19] in an investigation of unsafe pedestrian behaviour at LCs. The younger and middle age frequent LC users are the most likely to violate the traffic rules at LCs. Stefanova et al. [19] highlighted the importance of availability and clarity of information about rules for pedestrians using the LCs.

The safety at LCs in the United States has been analysed by Saunders et al. [20] and they found that drivers violate traffic rules less during nighttime hours. However, the safety decreases with increasing volume of traffic in urban areas. The major violation of traffic rules at LCs were associated with medium traffic volume and at the weekends, particularly in urban areas. The results of analyses suggested that the major violation associated with passenger cars and minor violations with heavy vehicles. The factors influencing zigzag occurrence have been analysed by Liang et al. [21] and they did not find a relation between the closure cycle of LCs and rate of 'zigzag'. Liang et al. [21] infer that drivers are more likely to commit zigzag violations of the LCs located close to a railway station and on roads with higher traffic density. To prevent zigzag violations it is important to design a reasonable and consistent warning time for LCs.

The factors that affect the probability of injuries in accidents at public LCs was studied and nationwide data across the United States from 2009 to 2013 analysed by Haleem and Gan 
[22]. There were 6,362 registered accidents at public LCs and 2,488 of these accidents with injuries. The study identified potential injury severity predictors for crashes at LCs. The results of analyses show that high train speed, female drivers, older age drivers, open-space area and clear weather conditions associated an increase in probability of accidents resulting in injuries or fatalities, but higher Annual Average Daily Traffic (AADT), young and middle age drivers, existence of stop line markings reduced the probability of accidents resulting in injuries. Haleem and Gan [22] recommended to avoid location of new LCs in open-space areas, instead of this placed LCs in the vicinity of industrial areas, equip LCs with warning systems and install rumble strips before the LCs. The results of this study refuted the popular belief that as the number of cars increases, the number of accidents resulting in injuries at LCs also increases.

The accidents and fatalities at LCs not only damage the safety and reputation of the rail industry but also have a huge cost for society. In 2010, in Europe, this cost was estimated at $€ 350$ million [23]. The railway industry in the EU puts the huge effort to reduce the number of accidents at LCs. From 2009 to 2011 the number of accidents at LCs had been decreased from 831 to 528 and the number of fatalities decreased from 405 to 294 [24]. However, there is still near one fatal accident at LCs in the EU every day. Despite all efforts, the number of accidents at LCs in the EU in the last ten years remained stable [8]. Moreover, it has been found that the number of drivers and pedestrians who disobey the LC signals is increasing [25]. The marginal costs for LCs accidents in Sweden have been investigated by Jonsson et al. [26] and they found that accidents at LCs are almost always caused by non-observance of traffic rules by road users. With increasing the flow and speed of traffic, the probability of accidents at LCs will increase. Also, Jonsson et al. [26] concluded that probability of accidents at LCs will increase with increasing the population living nearby. The LCs represent a big operational risk, and the most logical thing would be for all of them to close, but it can restrict mobility in some places whilst building grade separation crossings is not always possible in built-up areas in countries such as the Netherlands or Japan and it is not always economically appropriate.

Figure 1 shows that there can be identified three groups of countries related to the number of significant accidents at LCs. The first group includes majority of the countries. In this group the number of accidents fluctuate between 2 and 20. This group includes countries

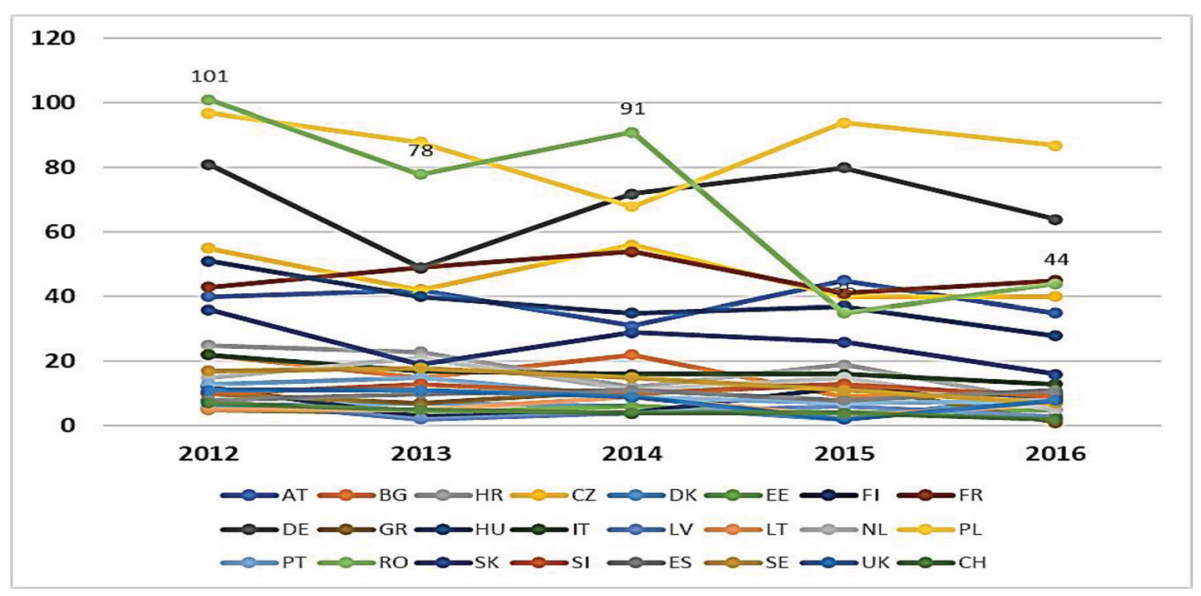

Figure 1: Number of significant accidents at LCs in the selected countries in the period 2012-2016. Data taken from [27]. 
such as Switzerland, Latvia and UK. The second group that can be allocated are countries with the number of accidents at LCs between 20 and 60 per year. This group includes countries such as Slovakia, Netherlands and Italy. The third group that can be allocated are countries with the number of accidents between 60 and 101. This group includes countries such as Romania, Poland and Germany.

\section{DATA ENVELOPMENT ANALYSIS (DEA) APPROACH}

Data envelopment analysis (DEA) is a method that measures the efficiency of similar decision-making units (DMUs) [28]. The DEA is a non-parametric method based on the assumption that the production function of fully efficient DMUs is not known [29]. The DEA was proposed in 1978 by Charnes, Cooper and Rhodes. In this research, railway systems are Decision-Making Units. Cook et al. [30] concluded that the number of DMUs must be at least twice the number of inputs and outputs combined.

This DEA analysis has been acknowledged before to benchmark the performance of DMUs and found the best practice. The efficiency of DMUs depends on their distance to the frontier. This methodology uses the ratios between outputs and inputs and compares all units and their relative efficiency with respect to the best performing unit. The efficiency score (1) for units is defined as the weighted sum of multiple outputs, $\sum_{k=1}^{r} U k Y k j$ divided by the weighted sum of multiple inputs $\sum_{i=1}^{m} V i X i j[31]$.

$$
\max h_{j}=\frac{\sum_{k=1}^{r} U k Y k j}{\sum_{i=1}^{m} V i X i j},
$$

where $h_{\mathrm{j}}$ is the maximum ratio of outputs to inputs, $k=1, \ldots, r$ is the sum of $k$ th positive output and $i=1, \ldots, m$ is the weight $i$ th positive inputs.

One advantage of applying DEA is that it can operate with multiple inputs and outputs, and it is not needed to clarify their importance. Other advantages are that it is suitable for small samples and has a small run time [32]. The DEA compares each railway system with all other railways and identifies railways that are operating inefficiently and find the target values of output and input for inefficient railways.

Emrouznejad and Yang [33] produced a bibliography of articles related to DEA which have been published since 1978. They found that in the last three years, interest in DEA methodology had grown rapidly and reached approximately 1,000 articles published every year.

Cavaignac and Petiot [34] concluded that only around $8 \%$ of the total number of articles that use DEA in transport analysis analyses railway transport. More than half of all articles using DEA in transport analysis used Constant Return to Scale (CCR) and Variable Return to Scale (BCC) approach and the second most popular is the two-stage DEA method when on the second stage Tobit regression analysis is used. Tobit regression was used at the final stage of DEA to evaluate the relationship between related factors and a variety of results.

Growitsch and Wetzel [35] analysed 54 railway companies using DEA to find out how regulatory environment affects the economic performance of European Railways. Amiril et al. [36] found that there are 27 sustainability factors that cover the performance of transportation infrastructure projects. They can be divided into environmental, economic, social, engineering/resource utilization and project management performance factors. 
Efficiency and effectiveness in railway performance applying a DEA model studied [37]. They selected 20 railways for the year 2002. Because they selected only one year, the results can be influenced by external causes that are not under railway control. The productivity growth in European railways was studied by Loizides and Tsionas [38]. They investigated 10 railroads of the EU from 1970 to 1992 . It was found that technical changes declining over time and only German and British railways have a positive technical change.

\section{THE INPUT AND OUTPUT-ORIENTED DEA MODELS}

There are input-oriented and output-oriented DEA models. The input-oriented model measures relative inputs under constant output, and the output-oriented model measures relative output under constant inputs. Some authors [39] pointed out that the level of demand for public transport is connected to demographic and macro-economic factors and railways have limited control on the level of demand. For the transport industry, it is typical that services cannot be stored because this outputs production seat-km can differ greatly from output consumption-passenger-km. The process of production differs from consumption. Yu and Lin [37] in their paper related to multi-activity network data envelopment analysis defined four performance measures: passenger technical efficiency, freight technical efficiency, service effectiveness (SE) and technical effectiveness (TE).

One of the major drawbacks of the DEA approach is the lack of discrimination among efficient DMUs [40]. To solve this problem, the Super Efficiency approach can be used. This method allows an efficiency score greater than 100 and provides a ranking of efficient DMUs in a similar way to a ranking of inefficient DMUs. This method was introduced for the first time by Andersen and Petersen [41].

The DEA method has been used to investigate the efficiency of the world's railways and effectiveness in reducing costs by Yu and Lin [37]. This analysis took aggregates of different disciplines of economy, mathematics and management science. Yu and Lin [37] found that using different DEA models to evaluate a railway's performance does not alter the ranking of performance.

Karlaftis [42] found that a transport system efficiency and effectiveness are positively correlated and systems with a high efficiency score have a higher effectiveness score. This led to two measures of transport output: vehicle-km and passenger-km. The author estimated three separate sets of models with the same inputs but with different outputs. The first is an efficiency model with vehicle-km as output, the second is an effectiveness model with a total annual ridership as output and the third is a multi-output model using vehicle-km and annual ridership as outputs to evaluate a combined performance.

Amirteimoori et al. [43] presented a DEA model that can analyse the situation when there are desirable and undesirable performance factors. An example of undesirable outputs can be air pollution and noise pollution. It is important to recognise desirable outputs and undesirable outputs and treat them differently. Sometimes, to improve the efficiency of DMUs some inputs must be increased and at the same time some outputs should be decreased.

Djordjević et al. [5] have used the improved non-radial DEA model which presumes to decrease the undesirable inputs and outputs to the greatest degree for the level of desirable inputs and outputs. The model calculates unified efficiency and reduces desirable inputs. The author used this model to evaluate railway efficiency regarding safety at LCs by considering desirable and undesirable outputs.

Some authors have highlighted that with European railways, it is not sure which model input-oriented or output-oriented must be used. Coelli and Perelman [39] estimated both the input and output distance functions. Both models identified the same sets of DMUs as being 
efficient. Lan and Lin [44] stressed that when applying the economic approach to estimate efficiency and effectiveness, it needs to specify which function will be more appropriate, the production or cost.

\section{MALMQUIST INDEX DEA MODEL}

Numerous studies have applied Malmquist index to measure productivity change over time, and it is very useful as it requires only information of input and output quantities and does not need to have information on input and output prices which would be difficult to obtain. The Malmquist index shows if there has been an improvement over time in productivity and in technical efficiency and how the railways perform compared to the best performer. If the Malmquist index is greater than one, it means that it was an improvement in productivity, and if less than one, it means that productivity decreases. The Malmquist index is calculated under CRS.

Sueyoshi et al. [45] had the Malmquist index to measure sustainable enhancement in Chinese municipalities and provinces. They studied a dynamic change of the Malmquist index to examine the frontier shift in the selected period. The main contribution of the study was to analyse the relationship between magnitude of index change and the managerial disposability. The drawback of the study was that the assessment was not considered under all the configurations on the scale benefit.

Zhang et al. [46] had the Malmquist index to measure dynamic change in total carbon emissions performance of the Chinese transport industry over the selected period. The Malmquist index had been decomposed into efficiency change and the technological change index. Zhou et al. [47] applied the Malmquist index to measure the environmental performance of OECD countries over time. This approach presumes including desirable and undesirable outputs that are jointly produced. One of the limitations of the study is that the proposed model has weak discrimination power and if DMUs have the efficiency index one they cannot be directly compared and ranked. In this situation there can be two solutions. Firstly, it can compare efficient DMUs by the number of peers. Secondly, it can use the super efficiency approach.

\section{INPUT ORIENTED DEA APPROACH}

To evaluate the safety at LCs for the whole railway system, it is a difficult task as railways have a difference in length of the railway network, technical approach, and different geographic locations.

More often the three approaches to use the DEA model was mentioned: traditional DEA model with CCR and BCC approach, traditional DEA models with Malmquist production index to operate with dynamic time series data and the two-stage network DEA model where output on the first stage will play input on the second stage.

The results of all DEA approaches include the measured efficiency of selected DMUs, setting benchmarks for inefficient DMUs, and quantified parameters for increasing the efficiency of inefficient DMUs. This method integrates and transforms multiple inputs and outputs into a single efficiency index with a set of DMUs.

To evaluate the efficiency of the selected railway systems the Malmquist production index was selected as it offers more advantages, such as it gives the possibility to find if improvements can be seen over time, it does not require information on input and output costs which would be difficult to obtain and it is suitable for the small number of DMUs.

In this research, the input-oriented developers Charnes, Cooper and Rhodes (CCR) DEA model have been applied. To evaluate the efficiency scores of the selected railways, one input was selected that is the number of accidents at LCs and two outputs the thousand tonnes of 
goods transported by railway and millions of passenger-km has been selected. The efficiency is defined as the ratio of the output to input, and this ratio must be equal or less than 1 . Table 1 shows the efficiency of input oriented CCR DEA for the selected countries in the period 2012-2016.

The technical efficiency of railways shows the efficiency of railways in terms of accident risk at LCs in the period 2012-2016. The highest efficiency scores for selected period 2012-2016 have UK and $\mathrm{CH}, 97.37 \%$ and $80.41 \%$, accordingly. The railways in the UK have been efficient for 4 out of 5 years. The railway system in the UK was efficient between 2012 and 2015, but in 2016 the efficiency score dropped to $86.87 \%$. The decrease in efficiency scores in the UK have happened despite reduction of a substantial number of LCs from 6,617 in 2012 to 6,117 in 2016 . The decreasing efficiency scores have been affected

Table 1: Efficiency of CCR input-oriented DEA for the selected countries 2012-2016 in \% (source: author's creation).

\begin{tabular}{lcccccc}
\hline Country & $\mathbf{2 0 1 2}$ & $\mathbf{2 0 1 3}$ & $\mathbf{2 0 1 4}$ & $\mathbf{2 0 1 5}$ & $\mathbf{2 0 1 6}$ & Mean \\
\hline AT & 23.97 & 10.88 & 19.79 & 4.6 & 8.66 & 13.58 \\
BG & 5.41 & 4.46 & 3.81 & 3.36 & 4.31 & 4.27 \\
HR & 4.23 & 2.05 & 5.3 & 1.08 & 4.2 & 3.37 \\
CZ & 14.4 & 8.88 & 10 & 5.02 & 7.22 & 9.1 \\
DK & 19.71 & 16.66 & 15.1 & 9.89 & 6.47 & 13.57 \\
EE & 85.39 & 39.12 & 37.01 & 14.47 & 14.95 & 38.19 \\
FI & 28.06 & 56.9 & 56.61 & 5.75 & 11.84 & 31.94 \\
FR & 38.38 & 32.79 & 23.05 & 6.69 & 20.58 & 24.3 \\
DE & 43.15 & 46.7 & 31.02 & 9.48 & 16.74 & 29.42 \\
GR & 2.17 & 2.68 & 1.48 & 0.29 & 12.18 & 3.76 \\
HU & 8.78 & 6.41 & 8.84 & 2.81 & 5.27 & 6.42 \\
IT & 38.41 & 49.83 & 44.76 & 11.91 & 40.65 & 37.11 \\
LV & 72.32 & 100 & 87.25 & 19.16 & 46.99 & 65.14 \\
LT & 94.28 & 34.41 & 33.31 & 33.09 & 20.07 & 43.03 \\
NL & 23.95 & 15.47 & 25.7 & 5.75 & 37.05 & 21.58 \\
PL & 22.72 & 11.18 & 20.5 & 4.93 & 7.54 & 13.37 \\
PT & 7.12 & 4.86 & 7.69 & 3.28 & 5.45 & 5.68 \\
RO & 5.27 & 2.84 & 3.41 & 3.26 & 3.53 & 3.66 \\
SK & 11.3 & 10.22 & 10.76 & 3.76 & 8.76 & 8.96 \\
SI & 15.11 & 5.12 & 11.01 & 2.83 & 6.09 & 8.03 \\
ES & 50.15 & 42.01 & 31.05 & 9.77 & 24.65 & 31.53 \\
SE & 36.94 & 20.19 & 27.75 & 12.21 & 28.42 & 25.1 \\
UK & 100 & 100 & 100 & 100 & 86.87 & 97.37 \\
CH & 82.2 & 85.7 & 100 & 34.13 & 100 & 80.41 \\
Mean & 34.73 & 29.56 & 29.82 & 12.81 & 22.02 & 25.79 \\
\hline & & & & & \\
\hline
\end{tabular}


by the decreased volume of goods transported by railways in the UK. The volume of goods transported by railways decreased from 115,225 thousand tonnes in 2012 to 78,549 thousand tonnes in 2016 , that amounted to $31.83 \%$. The decrease in the volume of goods transported by railways affected the efficiency score. The decreased volume of goods transported by railways in the UK can partly be explained by the congestion of railway lines. The passenger transportation by railways increased from 60,783 million passenger-km in 2012 to 68,010 million passenger-km in 2016, that amounted to $11.89 \%$.

The average efficiency score of the selected countries for the period 2012-2016 was $25.79 \%$. Despite substantial reduction of the number of LCs in Europe in the last ten years the number of accidents is still high. In 2017, there were 209 people injured at LCs around Europe [48]. The lowest number of LCs per $100 \mathrm{~km}$ of railway line in 2016 had NL, BG and SE, but the efficiency score for these countries was $37.05 \%, 4.31 \%$ and $24.65 \%$ accordingly. The lowest average efficiency score in 2016, which was less than 5\%, had BG, HR, GR and RO. The highest number of LCs per $100 \mathrm{~km}$ in 2016 had SE, AT and CZ. The efficiency score in these countries was $28.42 \%, 8.66 \%$ and $7.22 \%$ accordingly. AT and CZ had efficiency scores substantially lower than average. It looks that the low number of LCs per $100 \mathrm{~km}$ of railway line does not always have the huge impact on efficiency of railways in term of accident risk. There is a need to look for other factors that can influence the efficiency scores. For this reason, there were seven factors selected that can influence the efficiency scores. They are the number of LCs in a country, population density, total length of railway lines, number of cars per 1,000 inhabitants, GDP per capita, median age of population in selected countries and crime index.

\section{IBM SPSS ANALYSES}

To find the relationship between the selected variables and efficiency of railways in terms of accident risk the IBM SPSS analytic software was applied. Only linear relationship is suitable for correlation analysis [49]. Figure 1 shows the Scatterplot of two variables, efficiency of railways in terms of accident risk at LCs and GDP per capita in the selected countries for the year 2016.

Figure 2 shows the strong positive relationship between GDPs per capita and efficiency of railways in terms of accident risk at LCs in the selected countries.

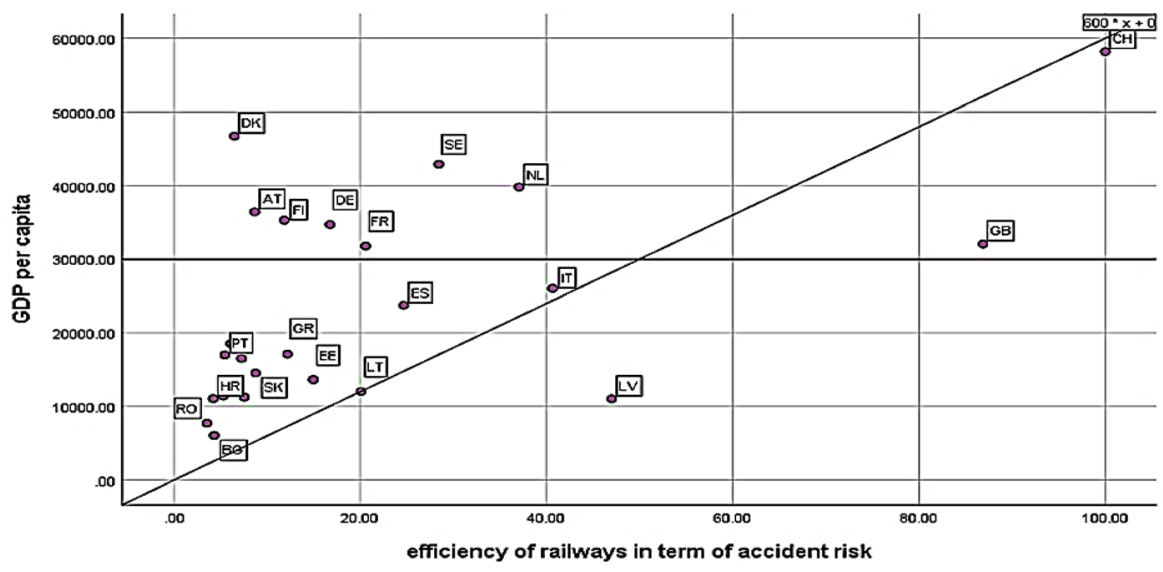

Figure 2: Scatterplot of efficiency of railways in terms of accident risk at LCs and GDP. 
Table 2: Summary of Pearson correlation test (source: author's creation).

\begin{tabular}{|c|c|c|c|c|}
\hline \multirow{5}{*}{$\begin{array}{l}\text { Efficiency } \\
\text { of railways } \\
\text { in term of } \\
\text { accident risk } \\
\text { at LC }\end{array}$} & Variables & $\begin{array}{l}\text { Pearson } \\
\text { correlation } \\
\text { coefficient }\end{array}$ & $\begin{array}{l}\text { Interpretation } \\
\text { of relationship }\end{array}$ & $\begin{array}{l}\text { Coefficient of } \\
\text { determination }\end{array}$ \\
\hline & $\begin{array}{l}\text { Number of LC by } \\
\text { country }\end{array}$ & -0.29 & Weak & $8.41 \%$ \\
\hline & Population density & 0.427 & Moderate & $18.23 \%$ \\
\hline & Road accidents & -0.352 & Moderate & $12.39 \%$ \\
\hline & GDP per capita & 0.538 & Strong & $28.94 \%$ \\
\hline
\end{tabular}

Eventually there was seven variables chosen; population density in a country, total length of railway lines in a country, number of cars per 1,000 inhabitants in the selected countries, GDP per capita, median age of population, crime index in a country and number of LCs in the selected countries, but only the variables showed the statistically significant relationship with efficiency of railways in terms of safety at LCs have been analysed.

Testing the Pearson correlation coefficient has been following a guideline [49] which states that the strength of the relationship is:

Small $r=0.10$ to 0.29 ; Medium $r=0.30$ to 0.49 ; Large $r=0.50$ to 1 .

Table 2 shows the relationship between efficiency of railways in terms of accident risk with selected variables. The coefficient of determination shows how much variance is shared by two selected variables or how much overlap there is between two variables [49].

\section{DISCUSSION AND ANALYSES}

The key factors affecting the efficiency of railways in terms of accident risk are:

Factor 1 - number of LCs in a country

The number of LCs in a country has a negative weak relationship with the efficiency of railways in term of accident risk at LCs. Countries such as France $(16,678)$, Germany $(14,054)$ and Poland $(13,109)$ have the highest number of LCs, and the efficiency of railways in the term of accident risk at LCs is quite low as France has $20.58 \%$, Germany $16.74 \%$ and Poland $7.54 \%$.

Factor 2 - Population density

Population density has a positive moderate relationship with efficiency of railways in term of accident risk at a LC. From five countries (NL, IT, GB, CH and DE) with the highest level of density of population in Europe, four countries (NL, IT, GB and $\mathrm{CH}$ ) scored the highest level of efficiency of railways in term of accident risk at LCs. The score of efficiency of these railways in the term of accident risk at LCs for 2016 was $37.05 \%, 40.65 \%, 86.87 \%$ and $100 \%$ respectively. Only DE has a lower score of $16.74 \%$.

Factor 3 - Number of deaths per 100,000 people in road accidents in 2016

The number of deaths in road accidents has a negative moderate relationship with the efficiency of railways in terms of accident risk at a LC. The increasing number of deaths in road accidents decreases the efficiency of railways in terms of safety at LCs.

The number of road accidents in a country and efficiency of railways in terms of safety at LCs has a negative moderate relationship. It means that with the increasing number of 
road accidents in a country will decrease the efficiency of railways in terms of safety at LCs. The railways around the world are working on improving safety at LCs but not everything depends on the railways. Because of this when we compare performance of different railways around the world or in the EU there is a need to take in consideration factors that do not directly depend on the railways. For example, in Georgia (country in Caucasus region) only in the last few years the MOT of vehicles has been introduced.

Factor 4 - GDP per capita

GDP per capita has a strong positive relationship with efficiency of railways in terms of accident risk at LCs. Countries with the highest GDP per capita in 2016 of the selected ones in this study are CH, DK, SE, NL, AT, FI, DE, FR and GB. Five of them have the highest score of efficiency of railways in the term of accident risk at LCs for 2016. They are CH, GB, IT, NL and SE.

\section{CONCLUSIONS}

Railways around the world have benefited from the continuing improvement in the control and communication systems, but LCs remain a substantial safety risk. To reduce the number of accidents at LCs, there is a need to close them where it is necessary. Eliminating a LC can be cost effective but upgrading the LC very often can be expensive and not proportional to the risk reduction that was achieved.

It was found that many factors can influence the efficiency of railways in the term of accident risk. In this research, several factors were selected to investigate their relationship with efficiency scores, and it was found that the strongest relationship with efficiency scores has a number of LCs in a country, population density and GDP per capita.

The investigation shows there is a good correlation between the degree of economic development and the safety at railway LCs. Therefore, there is a need to take into consideration the level of economic development and density of population in that country. For some railways, improving the safety level at LCs is easier than for others where stagnation in economy and low density of population negatively affect performance of railways. There is an exception for this, the Baltic State countries [50]. GDP per capita in Euro in 2016 in LV was €11,030, LT was $€ 12,040$ and in EE was $€ 13,650$. Nevertheless, LV has a $46.99 \%$ efficiency score, the third highest score of efficiency of railways in terms of accident risk at LCs after $\mathrm{CH}$ with $100 \%$ and GB with $86.87 \%$. This can be explained by the low number of passenger cars on the roads and by low railway traffic. In $2016 \mathrm{LV}$ had one of the lowest numbers of passenger cars per 1,000 inhabitants, which was 341 cars. Romania had 261 and Hungary had 338 cars per 1,000 inhabitants. Also, LV had low passenger and freight traffic by railway. In 2016, LV transported 47,819 million tonnes of freight by railway which was substantially lower than the average in the selected countries which was 67,629 million tonnes.

To reduce the number of accidents, it is needed to better understand the local and human factors. It is crucial to increase the number of awareness campaigns and improves the cooperation between different road and railway institutions and stakeholders. Although, technology is fundamental to improving the safety at LCs, but safety can also be improved by educating the public and by enforcing related laws and regulations.

For further research additional factors can be investigated such as average age of motor vehicles in a country, road conditions and geographical location of countries. Also, it would be beneficial to study the near-miss accidents that usually will not be investigated due to the large number of events. 


\section{REFERENCES}

[1] World Life Expectancy, World Total Deaths, [online] available at https://www. worldlifeexpectancy.com/world-rankings-total-deaths 2020, 2020 (accessed 24 September 2020).

[2] Ec.europa.eu, Rail Accident Fatalities In The EU - Statistics Explained, [online] available at https://ec.europa.eu/eurostat/statistics-explained/index.php/Rail_accident_ fatalities_in_the_EU, 2020 (accessed 24 September 2020).

[3] Evans, A., The economics of railway safety. Research in Transportation Economics, [online] 43(1), pp. 137-147, available at https://www.sciencedirect.com/science/article/ abs/pii/S0739885912002077, 2013 (accessed 24 September 2020).

[4] Carrese, S., Petrelli, M. \& Renna, A., Safety at LCs in Italy: evidence from the SaferLC Project. Transportation Research Procedia, [online] 45, pp. 562-571, available at https://www.sciencedirect.com/science/article/pii/S2352146520302180, 2020 (accessed 25 September 2020).

[5] Djordjević, B., Krmac, E. \& Mlinarić, T., Non-radial DEA model: a new approach to evaluation of safety at railway level crossings. Safety Science, [online] 103, pp. 234-246, available at https://www.sciencedirect.com/science/article/pii/S0925753517302266, 2018 (accessed 27 September 2020).

[6] Doomernik, J., Performance and efficiency of high-speed rail systems. Transportation Research Procedia, [online] 8, pp. 136-144, available at https://www.sciencedirect. com/science/article/pii/S2352146515001258, 2015 (accessed 6 August 2019).

[7] Kallberg, V., Safety audits at Finnish level crossings. The Open Transportation Journal, [online] 5(1), pp. 80-87, available at https://opentransportationjournal.com/contents/ volumes/V5/TOTJ-5-80/TOTJ-5-80.pdf, 2011 (accessed 25 September 2020).

[8] Laapotti, S., Comparison of fatal motor vehicle accidents at passive and active railway level crossings in Finland. IATSS Research, [online] 40(1), pp. 1-6, available at https:// www.sciencedirect.com/science/article/pii/S0386111215000308, 2016 (accessed 25 September 2020).

[9] Mulvihill, C., Salmon, P., Beanland, V., Lenné, M., Read, G., Walker, G. \& Stanton, N., Using the decision ladder to understand road user decision making at actively controlled rail level crossings. Applied Ergonomics, [online] 56, pp. 1-10, available at https:// www.sciencedirect.com/science/article/abs/pii/S0003687016300308, 2016 (accessed 25 September 2020).

[10] Rudin-Brown, C., Lenné, M., Edquist, J. \& Navarro, J., Effectiveness of traffic light vs. boom barrier controls at road-rail level crossings: a simulator study. Accident Analysis \& Prevention, [online] 45, pp. 187-194, available at https://www.sciencedirect.com/science/ article/abs/pii/S0001457511001850, 2012 (accessed 27 September 2020).

[11] Tey, L., Wallis, G., Cloete, S. \& Ferreira, L., Modelling driver behaviour towards innovative warning devices at railway level crossings. Accident Analysis \& Prevention, [online] 51, pp. 104-111, available at https://www.sciencedirect.com/science/article/ abs/pii/S000145751200379X, 2013 (accessed 27 September 2020).

[12] Liang, C. \& Ghazel, M., A risk assessment study on accidents at French level crossings using Bayesian belief networks. International Journal of Injury Control and Safety Promotion, [online] 25(2), pp. 162-172, available at https://www.tandfonline.com/doi/ abs/10.1080/17457300.2017.1416480, 2017 (accessed 25 September 2020).

[13] Larue, G., Naweed, A. \& Rodwell, D., The road user, the pedestrian, and me: investigating the interactions, errors and escalating risks of users of fully protected level 
crossings. Safety Science, [online] 110, pp. 80-88, available at https://www.sciencedirect. com/science/article/pii/S0925753517310123, 2018 (accessed 26 September 2020).

[14] Uic-stats.uic.org, RAILISA STAT UIC, [online] available at https://uic-stats.uic.org/ select/\#widget_country, 2020 (accessed 31 October 2020).

[15] Aminmansour, S., Maire, F. \& Wullems, C., Near-Miss Event Detect ion at Railway Level Crossings, [online] available at https://ieeexplore.ieee.org/document/7008119, 2014 (accessed 26 September 2020).

[16] Evans, A. \& Hughes, P., Traverses, delays and fatalities at railway level crossings in Great Britain. Accident Analysis \& Prevention, [online] 129, pp. 66-75, available at https:// www.sciencedirect.com/science/article/abs/pii/S0001457519306979, 2019 (accessed 26 September 2020).

[17] Stefanova, T., Oviedo-Trespalacios, O., Freeman, J., Wullems, C., Rakotonirainy, A., Burkhardt, J. \& Delhomme, P., Contextual factors explaining risk-taking intentions at Australian level crossings. Safety Science, [online] 110, pp. 145-161, available at https:// www.sciencedirect.com/science/article/pii/S0925753517313115, 2018 (accessed 27 September 2020).

[18] Freeman, J. \& Rakotonirainy, A., Mistakes or deliberate violations? A study into the origins of rule breaking at pedestrian train crossings. Accident Analysis \& Prevention, [online] 77, pp. 45-50, available at https://www.sciencedirect.com/science/article/abs/ pii/S0001457515000263, 2015 (accessed 25 September 2020).

[19] Stefanova, T., Burkhardt, J., Filtness, A., Wullems, C., Rakotonirainy, A. \& Delhomme, P., Systems-based approach to investigate unsafe pedestrian behaviour at level crossings. Accident Analysis \& Prevention, [online] 81, pp. 167-186, available at https:// www.sciencedirect.com/science/article/abs/pii/S0001457515001281, 2015 (accessed 27 September 2020).

[20] Saunders, W., Mousa, S. \& Codjoe, J., Market basket analysis of safety at active highwayrailroad grade crossings. Journal of Safety Research, [online] 71, pp. 125-137, available at https://www.sciencedirect.com/science/article/pii/S0022437519306164, 2019 (accessed 26 September 2020).

[21] Liang, C., Ghazel, M., Cazier, O. \& El-Koursi, E., Analyzing risky behavior of motorists during the closure cycle of railway level crossings. Safety Science, [online] 110, pp. 115126, available at https://www.sciencedirect.com/science/article/pii/S0925753517311001, 2018 (accessed 26 September 2020).

[22] Haleem, K. \& Gan, A., Contributing factors of crash injury severity at public highwayrailroad grade crossings in the U.S. Journal of Safety Research, [online] 53, pp. 23-29, available at https://www.sciencedirect.com/science/article/pii/S0022437515000171, 2015 (accessed 29 September 2020).

[23] Era.europa.eu, Level crossings safety in the European Union. [online] available at http:// www.era.europa.eu/Document-Register/Documents/Level_crossing_safety_EU_2012. pdf, 2012a (accessed 9 January.2018).

[24] Ec.europa.eu, File: Number of persons killed and injured by type of accident and category of persons in EU-28, 2014 final.png - Statistics Explained, [online] available at http:// ec.europa.eu/eurostat/statistics-explained/index.php/File:Number_of_persons_killed_ and_injured_by_type_of_accident_and_category_of_persons_in_EU-28,_2014_final. png, 2017 (accessed 9 January 2018).

[25] Theaa.com, Level crossing safety | AA, [online] available at http://www.theaa.com/ motoring_advice/news/level-crossing-safety-more-drivers-playing-russian-roulette. html, 2011 (accessed 9 January 2018). 
[26] Jonsson, L., Björklund, G. \& Isacsson, G., Marginal costs for railway level crossing accidents in Sweden. Transport Policy, [online] 83, pp. 68-79, available at https:// www.sciencedirect.com/science/article/abs/pii/S0967070X19300599, 2019 (accessed 25 September 2020).

[27] United Nations Economic Commission for Europe, Accidents At Level Crossings By Type Of Level Crossing By Type, Accident Type, Country And Year-United Nations Economic Commission For Europe, [online] available at https://w3.unece.org/PXWeb2015/ pxweb/en/STAT/STAT_40-TRTRANS_06-TRRAILACC/ZZZ_en_TRRailLCacc_r. px/, 2020 (accessed 9 November 2020).

[28] Emrouznejad, A. \& Thanassoulis, E., PIM-DEAsoft-V3.0 User Guide. PIm-Limited, 2011.

[29] Bray, S., Caggiani, L. \& Ottomanelli, M., Measuring transport systems efficiency under uncertainty by fuzzy sets theory based data envelopment analysis: theoretical and practical comparison with traditional DEA model. Transportation Research Procedia, [online] 5, pp. 186-200, available at https://www.sciencedirect.com/science/article/pii/ S235214651500006X, 2015 (accessed 10 October 2019).

[30] Cook, W., Tone, K. \& Zhu, J., Data envelopment analysis: Prior to choosing a model. Omega, [online] 44, pp. 1-4, available at https://www.sciencedirect.com/science/ article/pii/S0305048313000947, 2014 (accessed 4 August 2019).

[31] Charnes, A., Cooper, W. \& Rhodes, E., Measuring the efficiency of decision-making units. European Journal of Operational Research, [online] 2(6), pp. 429-444, available at https://www.sciencedirect.com/science/article/abs/pii/0377221778901388, 1978 (accessed 4 August 2019).

[32] Nataraja, N. \& Johnson, A., Guidelines for using variable selection techniques in data envelopment analysis. European Journal of Operational Research, [online] 215(3), pp. 662-669, available at https://www.sciencedirect.com/science/article/abs/pii/ S0377221711006011, 2011 (accessed 9 October 2019).

[33] Emrouznejad, A. \& Yang, G., A survey and analysis of the first 40 years of scholarly literature in DEA: 1978-2016. Socio-Economic Planning Sciences, [online] 61, pp. 4-8, available at https://www.sciencedirect.com/science/article/pii/S0038012117300174, 2018 (accessed 4 August 2019).

[34] Cavaignac, L. \& Petiot, R., A quarter century of data envelopment analysis applied to the transport sector: A bibliometric analysis. Socio-Economic Planning Sciences, [online] 57, pp. 84-96, available at https://www.sciencedirect.com/science/article/pii/ S0038012116302816, 2017 (accessed 4 August 2019).

[35] Growitsch, C. \& Wetzel, H., Testing for economies of scope in European railways an efficiency analysis. Journal of Transport Economics and Policy, 43(Part 1), pp. 1-24, 2009.

[36] Amiril, A., Nawawi, A., Takim, R. \& Latif, S., Transportation infrastructure project sustainability factors and performance. Procedia - Social and Behavioral Sciences, [online] 153, pp. 90-98, available at https://www.sciencedirect.com/science/article/pii/ S187704281405486X, 2014 (accessed 23 November 2019).

[37] Yu, M. \& Lin, E., Efficiency and effectiveness in railway performance using a multiactivity network DEA model. Omega, [online] 36(6), pp. 1005-1017, available at https:// www.sciencedirect.com/science/article/pii/S0305048307000916, 2008 (accessed 4 August 2019). 
[38] Loizides, J. \& Tsionas, E., Productivity growth in European railways: a new approach. Transportation Research Part A: Policy and Practice, [online] 36(7), pp. 633-644, available at https://www.sciencedirect.com/science/article/pii/S0965856401000271, 2002 (accessed 6 August 2019).

[39] Coelli, T. \& Perelman, S., A comparison of parametric and non-parametric distance functions: with application to European railways. European Journal of Operational Research, [online] 117(2), pp. 326-339, available at https://www.sciencedirect.com/ science/article/abs/pii/S0377221798002719, 1999 (accessed 4 August 2019).

[40] Angulo-Meza, L. \& Lins, M., Review of methods for increasing discrimination in data envelopment analysis. Annals of Operations Research, [online] 116(1/4), pp. 225-242, available at https://link.springer.com/article/10.1023\%2FA\%3A1021340616758, 2002 (accessed 14 April 2019).

[41] Andersen, P. \& Petersen, N., A procedure for ranking efficient units in data envelopment analysis. Management Science, [online] 39(10), pp. 1261-1264, available at https:// pubsonline.informs.org/doi/abs/10.1287/mnsc.39.10.1261, 1993 (accessed 6 August 2019).

[42] Karlaftis, M., A DEA approach for evaluating the efficiency and effectiveness of urban transit systems. European Journal of Operational Research, [online] 152(2), pp. 354-364, available at https://www.sciencedirect.com/science/article/abs/pii/ S0377221703000298, 2004 (Accessed 6 August 2019).

[43] Amirteimoori, A., Kordrostami, S. \& Sarparast, M., Modeling undesirable factors in data envelopment analysis. Applied Mathematics and Computation, [online] 180(2), pp. 444-452, available at https://www.sciencedirect.com/science/article/abs/pii/ S0096300306000075, 2006 (accessed 6 August 2019).

[44] Lan, L. \& Lin, E., Measuring railway performance with adjustment of environmental effects, data noise and slacks. Transportmetrica, [online] 1(2), pp. 161-189, available at https://www.researchgate.net/publication/46557356_Performance_Measurement_ for_Railway_Transport_Stochastic_Distance_Functions_with_Inefficiency_and_ Ineffectiveness_Effects, 2005 (accessed 4 August 2019).

[45] Sueyoshi, T., Yuan, Y., Li, A. \& Wang, D., Methodological comparison among radial, non-radial and intermediate approaches for DEA environmental assessment. Energy Economics, [online] 67, pp. 439-453, available at https://www.sciencedirect.com/ science/article/pii/S0140988317302554, 2017 (accessed 6 August 2019).

[46] Zhang, N., Zhou, P. \& Kung, C., Total-factor carbon emission performance of the Chinese transportation industry: a bootstrapped non-radial Malmquist index analysis. Renewable and Sustainable Energy Reviews, [online] 41, pp. 584-593, available at https://www.sciencedirect.com/science/article/pii/S136403211400762X, 2015 (accessed 6 August 2019).

[47] Zhou, P., Poh, K. \& Ang, B., A non-radial DEA approach to measuring environmental performance. European Journal of Operational Research, [online] 178(1), pp. 1-9, available at https://www.sciencedirect.com/science/article/abs/pii/ S0377221706003407, 2007 (accessed 6 August 2019).

[48] Ec.europa.eu., Rail accident fatalities in the EU - Statistics Explained, [online] available at https://ec.europa.eu/eurostat/statistics-explained/index.php/Rail_accident_fatalities_ in_the_EU, 2020 (accessed 4 January 2020). 
[49] Pallant, J., SPSS Survival Manual, 1st ed., McGraw-Hill: London, UK, pp. 59,77, 2013.

[50] Watson I., Ali A. \& Bayyati A., Sustainability of HSR-comparative study. ICE Innovation in Railway Civil Engineering Journal, available at https://www.icevirtuallibrary.com/ doi/pdf/10.1680/jtran.18.00131.

[51] Watson, I., Ali, A. \& Bayyati, A., Factors affecting efficiency of railways in terms of safety at level crossings. WIT Transactions on the Built Environment, Vol 199, WIT Press, 2020, ISSN 1743-350 